\title{
ARTICLES
}

\section{Reactivity of Germ Cell Maturation Stage-Specific Markers in Spermatocytic Seminoma: Diagnostic and Etiological Implications}

\author{
Hans Stoop, Ruud van Gurp, Ronald de Krijger, Ad Geurts van Kessel, \\ Beate Köberle, Wolter Oosterhuis, and Leendert Looijenga
}

Department of Pathology (HS, RvG, WO, LL), Laboratory for Experimental Patho-Oncology, and Department of Pathology (RdK), University Hospital Rotterdam/Daniel den Hoed Cancer Center, Josephine Nefkens Institute, Erasmus University, Rotterdam; Department of Human Genetics (AGvK), University Medical Center, Nijmegen, The Netherlands; and Imperial Cancer Research Fund (BK), Clare Hall Laboratories, South Mimms, United Kingdom

SUMMARY: It is generally accepted that testicular seminomas and spermatocytic seminomas have separate pathogeneses, although the origin of these two types of germ cell tumors of the adult testis remains a matter of debate. Although an embryonic germ cell origin seems to be most likely for seminomas, a spermatogonia-spermatocyte origin has been suggested for spermatocytic seminoma. To shed more light on the etiology of spermatocytic seminomas, we undertook an immunohistochemical and molecular approach using SCP1 (synaptonemal complex protein 1), SSX (synovial sarcoma on X chromosome), and XPA (xeroderma pigmentosum type A) as targets. Although a stage-specific expression pattern has been reported for SCP1 and SSX in normal spermatogenesis, we demonstrate here that it also exists for XPA. In fact, immunohistochemistry shows that the proteins of SCP1 and XPA are specifically present in the stage of primary and pachytene spermatocytes. In contrast, SSX was found in spermatogonia and primary spermatocytes, as well as in germ cells, from at least the 17th week of intrauterine development onward. Although no protein encoded by any of these genes was detected in tumor cells of a series of testicular seminomas, all tested spermatocytic seminomas were positive, in agreement with expression analysis. These data support the model that seminomas originate from an embryonic germ cell, and they imply that the cell of origin of spermatocytic seminomas is at least capable of maturing to the stage of spermatogonia-pachytene spermatocyte. (Lab Invest 2001, 81:919-928).

$W$ ithin the human adult testis, two types of germ cell tumors are distinguished: (a) the seminomas and nonseminomas, known as testicular germ cell tumors of adolescents and adults (TGCTs), and (b) the spermatocytic seminomas (Mostofi and Sesterhenn, 1998). The TGCTs originate from carcinoma in situ (Skakkebæk, 1972), supposed to be the malignant counterpart of an embryonic germ cell. This view is based on the finding that, morphologically (Gondos, 1993) and immunohistochemically, carcinoma in situ (and seminoma) shows similarities to embryonic germ cells, including their positivity for placental/germ cell alkaline phosphatase (Roelofs et al, 1999), stem cell factor receptor C-KIT (Rajpert-De Meyts and Skakkebæk, 1994), and glycogen (Mostofi and Sesterhenn,

Received November 13, 2000

This work was supported by a grant from the Dutch Cancer Society (KWF). Address reprint requests to: Dr. L. H. J. Looijenga, Pathology/Laboratory for Experimental Patho-Oncology, University Hospital Rotterdam/Daniel, Josephine Nefkens Institute, Erasmus University Building Be, Room 430b, P.O. Box 1738, 3000 DR Rotterdam, The Netherlands. Email: Looijenga@leph.azr.nl
1998). Moreover, epidemiological data indicate that the initiating event in the pathogenesis of TGCTs occurs during intrauterine development (Møller, 1989). TGCTs are aneuploid, with a characteristic pattern of gains and losses of chromosomal material (Oosterhuis et al, 1989; Rosenberg et al, 1999; Van Echten-Arends et al, 1995).

It is generally accepted that spermatocytic seminomas have a different pathogenesis from TGCTs. Morphological analyses indicate that the tumor cells may undergo part of meiosis (Romanenko and Persidskii, 1983; Rosai et al, 1969; Walter, 1980), although other studies do not support this contention (Eble, 1994; Takahashi, 1993; Talerman, 1980). No carcinoma in situ has been identified in the adjacent parenchyma of spermatocytic seminomas (Burke and Mostofi, 1993; Eble, 1994; Mostofi and Sesterhenn, 1998; Rosenberg et al, 1998). In contrast, the precursor lesion of spermatocytic seminoma is known as intratubular spermatocytic seminoma, which fills up the seminiferous tubule, suggesting that the cell of origin resides on the luminal side of the tight junctions present between Sertoli cells. Most spermatocytic seminomas are neg- 
ative for placental/germ cell alkaline phosphatase (Cummings et al, 1994; Dekker et al, 1992) and glycogen (Burke and Mostofi, 1993; Eble, 1994; Mostofi and Sesterhenn, 1998). Although an increasing incidence has been shown for TGCTs during recent decades (Adami et al, 1994), no such phenomenon has been reported for spermatocytic seminoma.

Although morphologically carcinoma in situ and seminoma cells are rather homogeneous, three types of cells are identified in spermatocytic seminomas: those with small, intermediate, and large nuclei (Eble, 1994; Romanenko and Persidskii, 1983; Rosai et al, 1969; Talerman, 1980). This is in agreement with data from flow cytometric analysis, as well as from in situ hybridization experiments (Kraggerud et al, 1999; Kysela and Matoska, 1991; Looijenga et al, 1994; Rosenberg et al, 1998; Takahashi, 1993; Talerman et al, 1984). These investigations show that at least a diploid tumor cell population is present. We demonstrated recently that spermatocytic seminomas have a completely different chromosomal constitution from seminomas and nonseminomas (Rosenberg et al, 1998).

We questioned whether spermatocytic seminomas indeed originate from a cell that is able to undergo (partial) meiosis. Therefore, we studied the presence of mRNA and proteins of three genes, two of which have a specific pattern of expression during male germ cell development. In fact, synovial sarcoma on $\mathrm{X}$ chromosome (SSX) is mainly found in spermatogonia (Dos Santos et al, 2000) and synaptonemal complex protein 1 (SCP1) in cells undergoing meiosis, in particular, meiotic prophase (Meuwissen et al, 1992; Tureci et al, 1998). Moreover, we show here that xeroderma pigmentosum type A (XPA) protein is predominantly found in pachytene spermatocytes. Antibodies against these proteins were applied to a series of frozen and formalin-fixed, paraffin-embedded seminomas and spermatocytic seminomas. Although seminomas were found to be negative, in agreement with an embryonic germ cell origin, all spermatocytic seminomas were positive. These antibodies are therefore suitable for distinguishing seminoma from spermatocytic seminoma in a clinical setting. In addition, the results support the idea that carcinoma in situ originates from an embryonic germ cell and indicate that spermatocytic seminomas originate from a cell capable of differentiating toward the primarypachytene-spermatocyte stage of development.

\section{Results}

\section{Antibody Specificity and Staining Patterns during Normal Germ Cell Development}

Recently, specific antibodies for SSX (recognizing subtypes 2-4) and SCP1 have been reported (Dos Santos et al, 2000; Meuwissen et al, 1992; Pousette et al, 1997; Schmekel et al, 1996). They were found to stain certain stages of male germ cell development in rodent (Heyting et al, 1989; Meuwissen et al, 1992) and human (Dos Santos et al, 2000; Pousette et al,
1997), in particular spermatogonia and primary spermatocytes. These patterns were confirmed by us (Fig. $1, A$ and B). The antibodies against SSX were specifically developed for formalin-fixed, paraffinembedded tissues and were used as such. In contrast, the antibodies for SCP1 are only applicable on frozen tissue, and despite different methods of antigen retrieval, no consistent staining could be obtained on formalin-fixed, paraffin-embedded material (data not

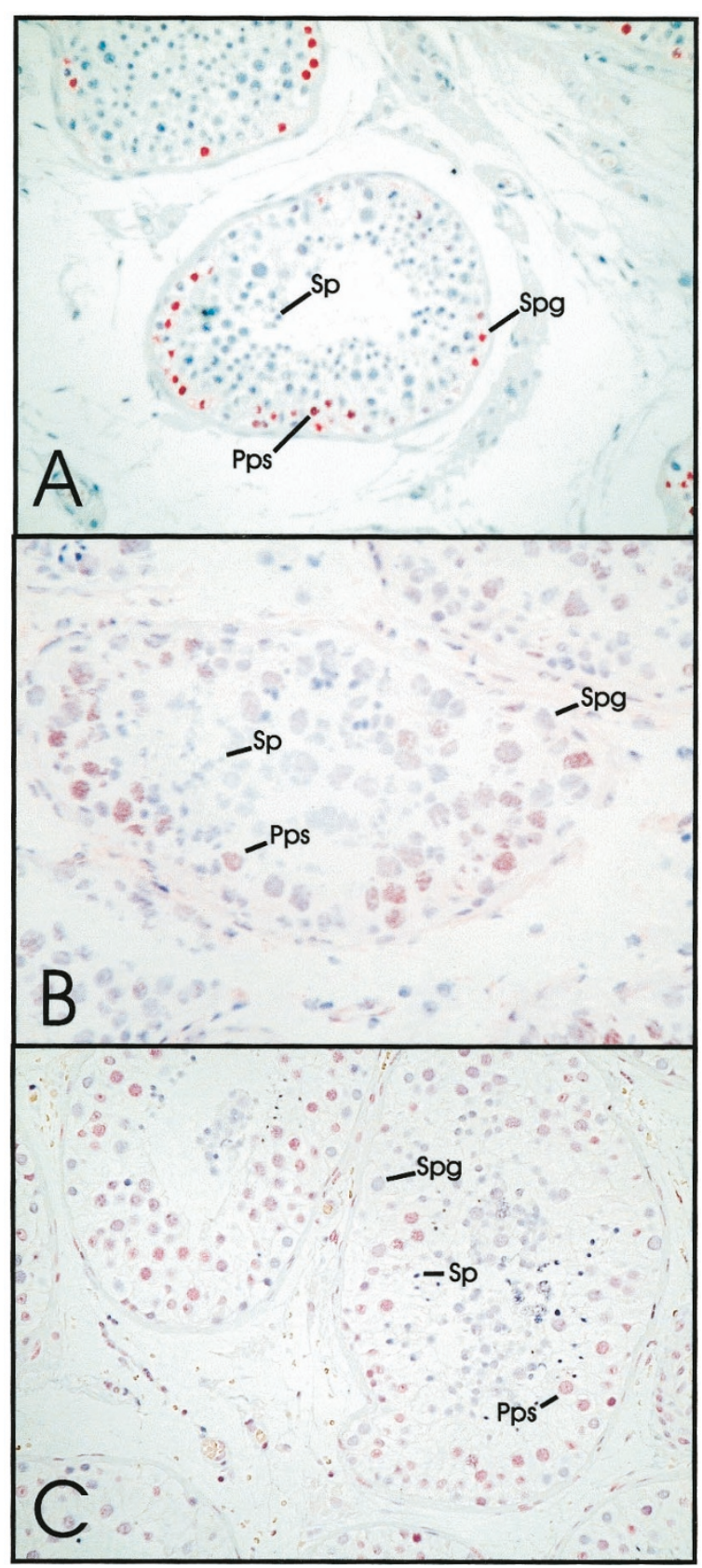

Figure 1.

Representative examples of the immunohistochemical detection of $(A)$ synovial sarcoma on $X$ chromosome (SSX), (B) synaptonemal complex protein 1 (SCP1), and (C) xeroderma pigmentosum type A (XPA) on testicular parenchyma with normal spermatogenesis. Analysis for SCP1 is done on frozen tissue, whereas SSX and XPA are done on formalin-fixed, paraffin-embedded tissue. Note the positivity of the germ cells at various stages of maturation. Spg, spermatogonia; Pps, primary and pachytene spermatocytes; Sp, spermatids. 
shown). Therefore, all results with the antibodies against SCP1 were obtained from snap-frozen cases. Antibodies against XPA have been available; however, their specificity has not been investigated extensively.
Here, we demonstrate that these antibodies do not stain XP12RO cells transfected with an empty vector (Fig. 2A). In contrast, XP12RO cells transfected with the same vector, but now also containing the XPA

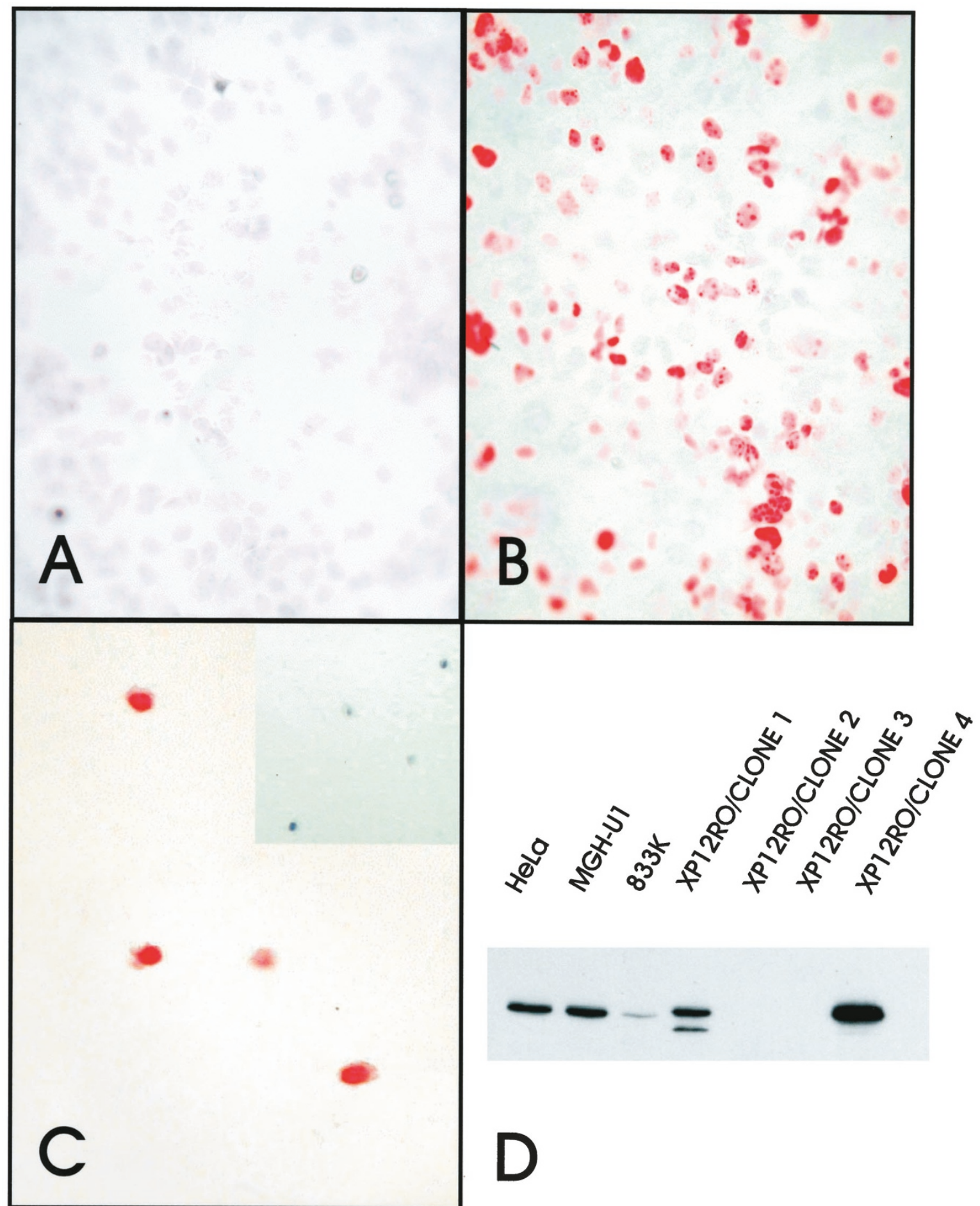

Figure 2.

Results of the analysis of specificity of the antibodies against XPA. Immunohistochemistry was performed on (A) XP12RO cells transfected with an empty vector, showing no staining; (B) XP12R0 cells transfected with the same vector including the XPA cDNA, showing positivity; and (C) HeLa cells, also showing positivity (insert represents the negative control). All cells were fixed with formalin and embedded in paraffin. The XP12RO cells were stained directly on the tissue well-plates in which they were grown. D, Western blot analyses of HeLa, MGH-U1 (a bladder cancer cell line), 833K (a germ cell tumor cell line), XP12R0 clones 1 and 4 (transfected with the pcDNA3.1 XPA-cDNA containing vector), and XP12R0 clones 2 and 3 (empty vector). Note that all samples are positive, except the XP12R0 cells transfected with the empty vector. 
cDNA, are positive (Fig. 2B). The specificity of these antibodies was confirmed using the same immunohistochemistry-approach on formalin-fixed, paraffin-embedded HeLa cells, which are known to contain XPA (Fig. 2C). This specificity was confirmed using Western blot analysis (Fig. 2D), showing a band of 40-42 kd. We serendipitously found that these antibodies specifically stain some of the pachytene spermatocytes present in testicular parenchyma with normal spermatogenesis (Fig. 1C).

To investigate from which stage onwards germ cells show positivity for SSX in particular, we studied 14 formalin-fixed, paraffin-embedded testes in different developmental stages, from 17 weeks to full term, and one testis of 7 months post partum (Table 1). For this latter case, as well as for an additional gonad of 36 weeks of development, frozen material was available. As expected, no positivity was found for XPA at any of the stages studied, and no SCP1 was found in the frozen specimens (data not shown). In contrast, SSX was present in germ cells in all testes at different developmental stages (Fig. 3A). As controls, immunohistochemistry was performed using antibodies against c-KIT and placental/germ cell alkaline phosphatase. Positivity for both proteins was found in germ cells at the different stages of intrauterine development (Fig. 3,B and C). The highest number of germ cells positive for C-KIT was observed in our series from the first developmental stage onwards (17th week) to the 21st week of development. Double-staining analysis revealed that embryonic germ cells positive for C-KIT can be either positive or negative for SSX (Fig.
3D). Germ cells positive for only SSX were also found. This is in accordance with the results found in the post partum specimens (data not shown).

\section{Staining Patterns of Testicular Seminoma and Spermatocytic Seminoma}

Using the antibody against SCP1, snap frozen spermatocytic seminomas (cases detailed in Rosenberg et al, 1998), and seminomas were stained (Table 1). Although all seminomas were negative (Fig. 4A), spermatocytic seminomas showed a consistent positive staining (Fig. 4B). In addition, all carcinoma in situ cases found adjacent to invasive TGCTs were negative (data not shown). A similar staining pattern was observed for the other two antibodies, recognizing SSX and XPA, respectively, although they were used on formalin-fixed, paraffin-embedded cases. In fact, no positivity was observed in the majority of seminomas (Fig. 4C and E). Three out of the 25 cases tested showed sporadically SSX-positive cells throughout the tissue section. Analysis of the matched samples containing carcinoma in situ showed no positivity (not shown). In contrast, all spermatocytic seminomas were homogeneously positive for both SSX and XPA (Fig. 4, D and F). Spermatogonia present in the seminiferous tubules entrapped in the seminoma component still showed positivity for SSX (Fig. 4C, arrow). A staining pattern similar to that in the invasive spermatocytic seminoma component was found in intratubular spermatocytic seminoma (data not shown). Some of the infiltrating lymphocytes present both in

Table 1. Results of Immunohistochemical Detection of SCP1, SSX, XPA, AP, and c-KIT on Germ Cells at Different Stages of Development, as well as in Seminomas and Spermatocytic Seminomas

\begin{tabular}{|c|c|c|c|c|c|c|c|}
\hline Histology & $\begin{array}{c}\text { Age } \\
\text { (wks) }\end{array}$ & No. & SCP1 & SSX & XPA & $\mathrm{AP}$ & C-KIT \\
\hline \multirow[t]{11}{*}{ Embryonic testis } & 17 & 1 & ND & + & - & \pm & +++ \\
\hline & 19 & 1 & ND & + & - & - & + \\
\hline & 21 & 2 & ND & + & - & \pm & +++ \\
\hline & 23 & 1 & ND & + & - & \pm & ++ \\
\hline & 24 & 1 & ND & + & - & \pm & ++ \\
\hline & 28 & 1 & ND & + & - & \pm & + \\
\hline & 35 & 2 & ND & + & - & \pm & + \\
\hline & 36 & $1^{a}$ & - & + & - & \pm & + \\
\hline & 37 & 1 & ND & + & - & \pm & + \\
\hline & 38 & 1 & ND & + & - & $-b$ & \pm \\
\hline & 40 & 1 & ND & + & - & - & $-{ }^{b}$ \\
\hline Post partum & 28 & $1^{a}$ & - & + & - & - & - \\
\hline Seminoma $^{d}$ & & & $-(6)$ & $-(25 / 3)^{b}$ & $-(25)$ & $+(\text { all })^{c}$ & $+(\text { all })^{C}$ \\
\hline Carcinoma in situ ${ }^{d}$ & & & $-(3)$ & $-(12)$ & $-(12)$ & $+(\text { all })^{c}$ & $+(\text { all })^{C}$ \\
\hline $\begin{array}{l}\text { Spermatocytic } \\
\text { seminoma }^{d}\end{array}$ & & & $+(4)$ & $+(13)$ & $+(13)$ & $-(13)$ & $-(11)$ \\
\hline Intratubular variant ${ }^{d}$ & & & ND & $+(11)$ & $+(2)$ & $-(2)$ & $-(11)$ \\
\hline
\end{tabular}

SCP1, synaptonemal complex protein 1; SSX, synovial sarcoma on X chromosome; XPA, xeroderma pigmentosum type A; c-KIT, stem cell factor receptor; AP, placental/germ cell alkaline phosphatase; ND, not determined.

Staining intensity: +++ , very strong; ++ , strong; + , weak; - , negative.

${ }^{a}$ Frozen.

${ }^{b}$ Sporadically weakly positive cells.

${ }^{c}$ We applied AP and C-KIT routinely on all collected seminomas, and so far no negative cases have been identified (more than 50 tested).

${ }^{a}$ Number of cases studied is shown in parentheses. 


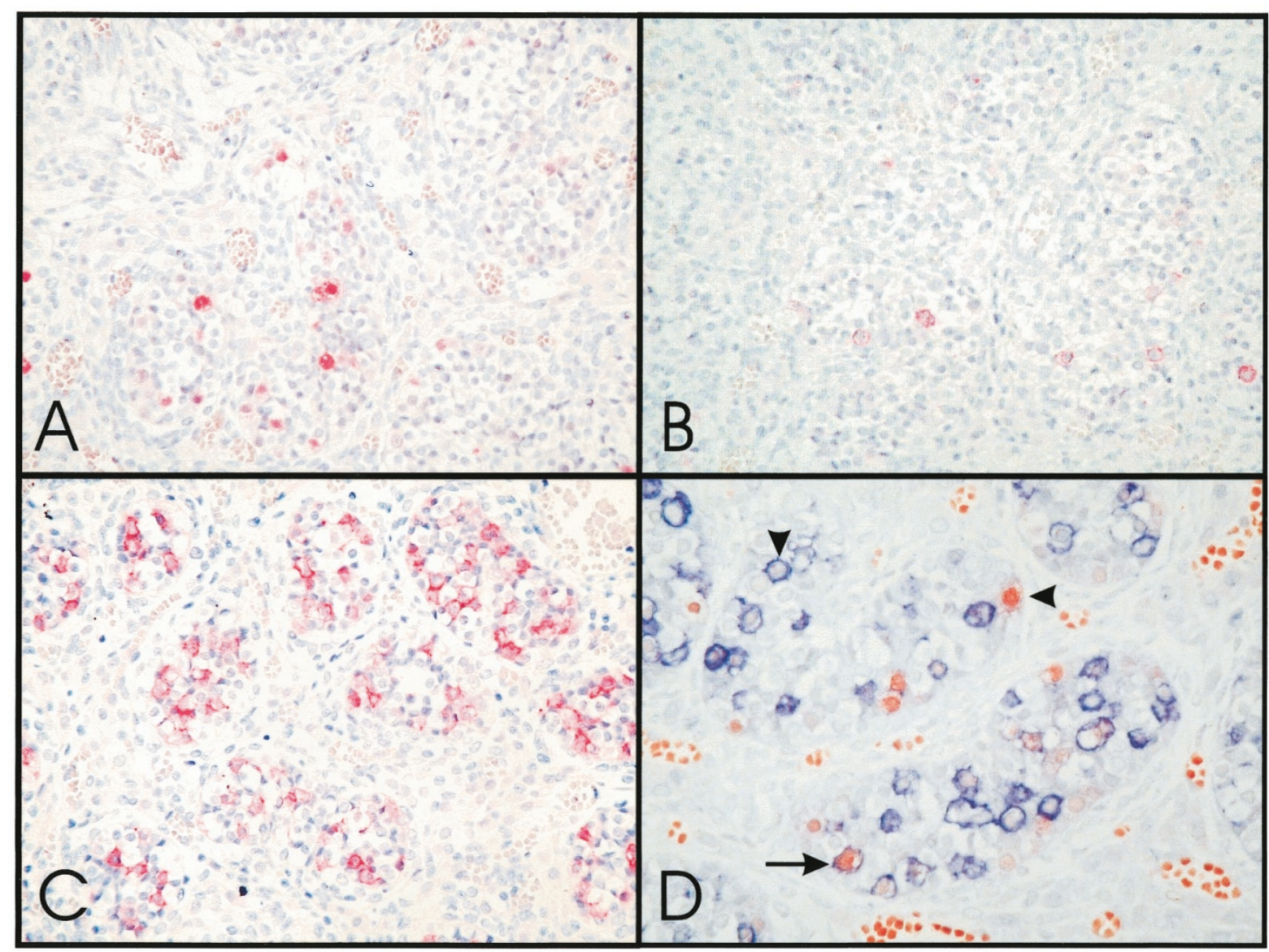

Figure 3.

Representative examples of the staining patterns in a testis sample after 17 weeks of intra-uterine development. Shown are (A) SSX; (B) placental/germ cell alkaline phosphatase; (C) C-KIT; and (D) double staining for SSX and C-KIT. Note the high number of germ cells positive for c-KIT and the lesser numbers for SSX and placental/germ cell alkaline phosphatase. The double-staining analysis demonstrated that c-KIT-positive germ cells can be positive (arrow) or negative for SSX (vertical arrowhead). In addition, germ cells positive for SSX only are also present (horizontal arrowhead).

seminoma and spermatocytic seminoma were positive for XPA (Fig. 4, E and F, arrowheads). None of the spermatocytic seminomas were positive for c-KIT in our investigation (data not shown), in contrast to earlier findings by others (Kraggerud et al, 1999).

\section{mRNA Analysis of SCP1, SSX3, and XPA}

To verify the data obtained by immunohistochemistry, we performed a semiquantitative reverse transcription-polymerase chain reaction (RT-PCR) analysis for all three genes, using HPRT as a control gene. Although the antibodies against SSX recognize the SSX 2, 3, and 4 subtypes, we only investigated expression of SSX3, as was done before (Dos Santos et al, 2000). As a positive control, testicular parenchyma containing normal spermatogenesis was used. This sample was immunohistochemically positive for all three targets (see above). A moderate level of expression was observed in normal testicular parenchyma for the corresponding genes (Fig. 5, Normal testis). The increase in the intensity of the bands indicates that the aliquots are taken during the linear range of amplification within the specific experiment. In agreement with immunohistochemistry, no mRNA or a low level of mRNA of the genes SCP1 and SSX (indicated by the arrow) was found in seminomas, whereas all spermatocytic seminomas showed a higher level of expression (Fig. 5, upper and middle panels). In contrast, expression of XPA was found in both seminomas and spermatocytic seminomas (Fig. 5 , lower panel). This is likely due to the characteristically greater number of infiltrating lymphocytes in seminoma compared with spermatocytic seminoma (Mostofi and Sesterhenn, 1998), although posttranslational modification cannot be ruled out.

\section{Discussion}

To shed more light on the origin of spermatocytic seminomas, we investigated the presence of proteins and the corresponding mRNAs of three genes showing positivity at specific stages of normal germ cell development. These include SCP1, a protein involved in the pairing of homologous chromosomes, which is present in the meiotic prophase of both rodent and human spermatocytes (Meuwissen et al, 1992; Pousette et al, 1997; Sage et al, 1999; Schmekel et al, 1996). Our immunohistochemical results demonstrated that the protein is indeed present in primary 


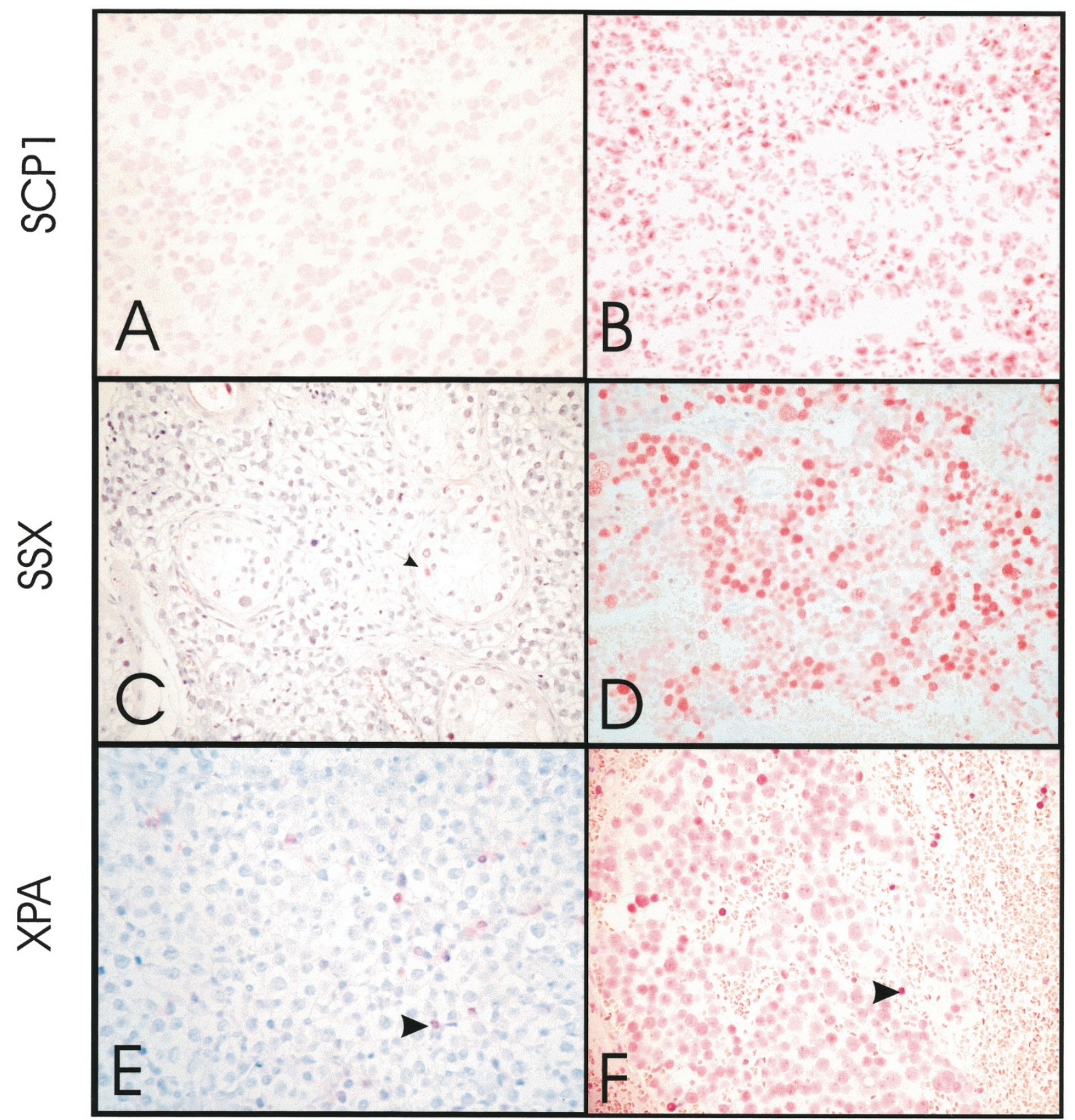

Figure 4.

Representative examples of the immunohistochemical detection in seminoma and spermatocytic seminoma, respectively, of SCP1 (A and B), SSX (C and D), and XPA (E and F). The analyses for SCP1 are done on frozen tissue and for SSX and XPA on formalin-fixed, paraffin-embedded tissue. Note the positivity for all three markers in spermatocytic seminoma, and their negativity in seminoma. C, SSX positivity is observed in a spermatogonial cell (arrow) and not in the seminoma and carcinoma in situ cells. Infiltrating lymphocytes can be positive for XPA as indicated by arrowheads in E and F.

and pachytene spermatocytes. In addition, the recently reported antibody E3AS, recognizing the SSX proteins 2-4, mainly stains spermatogonia and, more weakly, primary spermatocytes (Dos Santos et al, 2000, and this paper). We demonstrated that the SSX protein is already present in germ cells from the 17th week of intrauterine development onward. Although some of these germ cells were also positive for C-KIT (the stem cell factor receptor), others were negative. It would be of interest to determine from which stage onward SSX is positive in germ cells, although the samples required for such an analysis were not available. We serendipitously found that a specific antibody against XPA protein stains pachytene spermatocytes. No positivity was identified in earlier stages of germ cell development. XPA is involved in nucleotide 

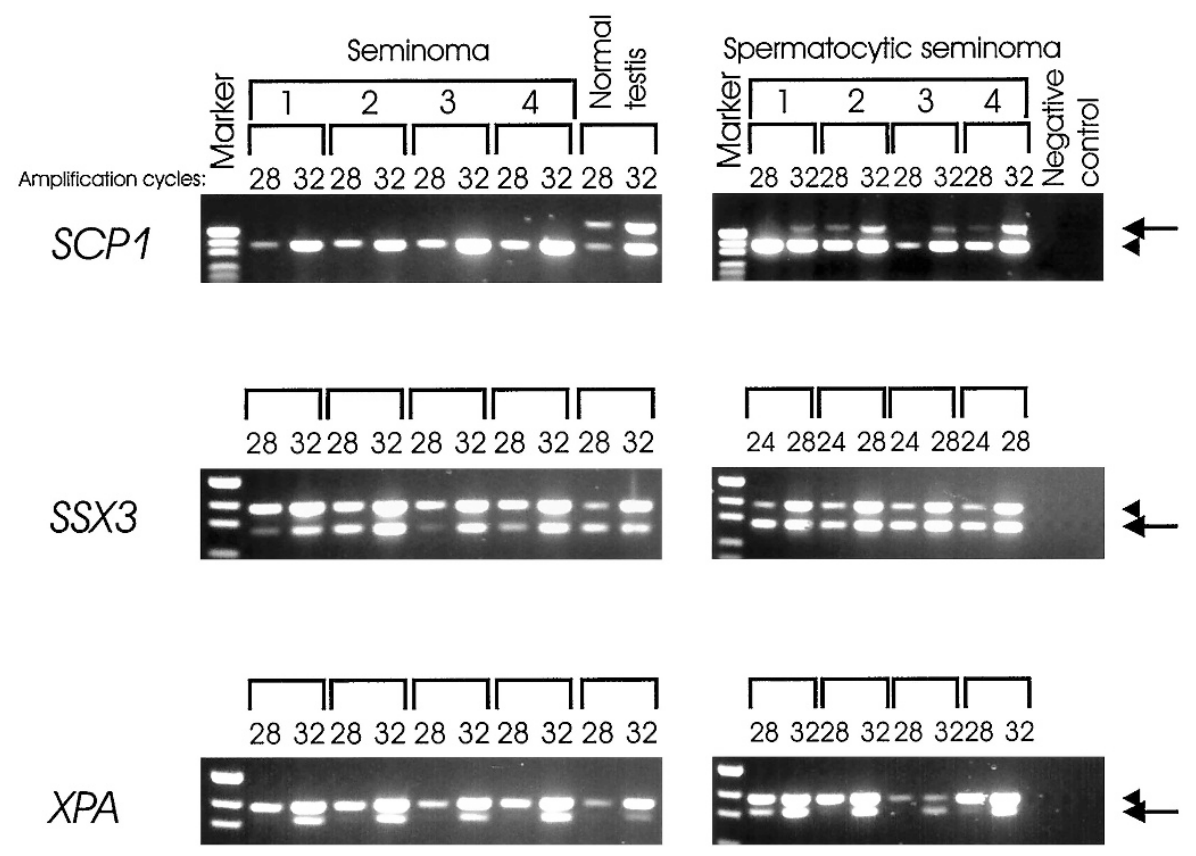

Figure 5.

Results of the semiquantitative reverse transcription-polymerase chain reaction (RT-PCR) analysis of the expression levels of SCP1 (upper panel), SSX3 (middle panel), and XPA (lower panel) (arrows), compared with HPRT (arrowheads). Note a consistently lower level of expression of SCP1 and SSX in the seminomas (1-4) compared with the spermatocytic seminomas (1-4), and a similar level for XPA. Note that, in the case of analysis of expression levels of SSX3 in spermatocytic seminomas, 24 and 28 amplification cycles, instead of 28 and 32, were performed.

excision repair (Wood, 1999), and although our finding of the specific positivity of this protein during spermatogenesis is novel and of interest, XPA does not seem to be crucial for normal male germ cell development, because XPA-knockout mice are fertile (de Vries and van Steeg, 1996). In conclusion, immunohistochemistry using antibodies against SCP1, SSX, and XPA can distinguish various stages of human spermatogenesis: SCP1 and XPA for primary and pachytene spermatocytes and SSX for germ cells at different stages of maturation.

In contrast to seminoma and carcinoma in situ, all spermatocytic seminomas are homogeneously positive for the three proteins tested, which was supported by expression analysis. Although seminoma and carcinoma in situ are consistently positive for c-KIT and placental/germ cell alkaline phosphatase (Rajpert-De Meyts and Skakkebæk, 1994; Roelofs et al, 1999), the spermatocytic seminomas are overall negative (Dekker et al, 1992 and this paper). The positivity of spermatocytic seminoma for SCP1 and SSX can, in our view, not simply be explained because they belong to the group of so-called cancer/testis antigens. This is indicated by the fact that all spermatocytic seminomas are positive, whereas, in general, only a minority of cancers are positive for this kind of antigen (Tureci et al, 1998). In contrast, the limited number of cells found to be positive for SSX in three seminomas might be related to this phenomenon. We conclude therefore, that spermatocytic seminoma originates from the nonmalignant counterpart during spermatogenesis, which is positive for all these markers, ie, a cell in the primary-pachytene spermatocyte stage of development. This would fit with the finding that the tumor cells of spermatocytic seminoma go through the first steps of meiosis (Eble, 1994; Romanenko and Persidskii, 1983; Rosai et al, 1969; Walter, 1980). The data obtained from genomic analyses, revealing diploid, tetraploid, and aneuploid nuclei (Kraggerud et al, 1999; Kysela and Matoska, 1991; Looijenga et al, 1994; Rosenberg et al, 1998; Takahashi, 1993; Talerman et al, 1984), and from morphology, showing small, intermediate, and large cells (Eble, 1994; Romanenko and Persidskii, 1983; Rosai et al, 1969; Talerman, 1980), might be the consequence of this process. Based on our data, it cannot, however, be excluded that the initiating event in the pathogenesis of spermatocytic seminoma affects an embryonic germ cell. This could be a cell positive for SSX and negative for c-KIT and placental/germ cell alkaline phosphatase, a cell type that we demonstrated appears in the testis during intrauterine development. Alternatively, this initiating event could affect a cell positive for all these markers, a cell that has lost c-KIT and most of the placental/germ cell alkaline phosphatase during further maturation toward a primarypachytene spermatocyte. As part of this maturation process, XPA will become positive. This latter possibility would explain the existence of bilateral spermatocytic seminoma (Burke and Mostofi, 1993) with a very similar chromosomal constitution (Rosenberg et al, 1998).

The results presently support the generally accepted view that TGCTs, ie, seminomas and nonseminomas, originate from an earlier stage of germ cell development than spermatocytic seminoma, most likely an embryonic germ cell, leading to carcinoma in situ. In fact, this most likely affects a cell positive for 
C-KIT and placental/germ cell alkaline phosphatase and negative for SSX, as can be found in the embryonic testis. Interestingly, the putative nonmalignant counterpart of carcinoma in situ has been suggested to be present around the 9th to 10th week of intrauterine development (Jørgensen et al, 1995), which would be in accordance with our present findings. This is also in agreement with epidemiological data (Adami et al, 1994), immunohistochemical findings (Cummings et al, 1994; Heidenreich et al, 1998; Hittmair et al, 1996; Rajpert-De Meyts and Skakkebæk, 1994; Roelofs et al, 1999), and expression analysis of human endogenous retrovirus $\mathrm{K}$ (HERV-K)-specific transcripts (Herbst et al, 1999; Roelofs et al, 1998). These markers are overall negative in normal spermatogenesis and spermatocytic seminomas, and positive in TGCTs. The monoclonal antibody $\mathrm{KI}-\mathrm{A} 10$ and telomerase activity are not informative in this context, because these are positive in normal spermatogenesis, seminoma, and spermatocytic seminoma (Delgado et al, 1999; Rudolph et al, 1999).

In conclusion, our immunohistochemical and expression data suggest that spermatocytic seminoma originates from a cell capable, at least, of maturating to a stage of the primary-pachytene spermatocyte. This study allows, for the first time, a conclusion about the origin of spermatocytic seminoma based on positive observations. Immunohistochemistry, using the antibodies against SCP1 (only applicable on frozen material), SSX, and XPA (also applicable on formalinfixed, paraffin-embedded material), is a positive marker distinguishing seminoma from spermatocytic seminoma. So far, the antibodies used in the differential diagnosis of spermatocytic seminoma demonstrated absence of antigens in spermatocytic seminoma compared with other entities.

\section{Materials and Methods}

\section{Samples}

The freshly obtained tumor specimens included in this study, ie, 6 seminomas and 4 spermatocytic seminomas, were collected in close collaboration with urologists and pathologists in the southwestern part of the Netherlands. All tumors were obtained before chemotherapy and/or irradiation. Directly after surgical removal, representative parts of the tumor and adjacent normal tissue (when available) were snap frozen and other pieces were fixed overnight in 10\% buffered formalin and embedded in paraffin. The tumors were diagnosed according to the World Health Organization (WHO) classification for testicular tumors (Mostofi and Sesterhenn, 1998). Identification of carcinoma in situ and seminoma was aided by a direct enzymehistochemical detection of alkaline phosphatase activity on representative frozen tissue sections, as reported before (Mosselman et al, 1996). In addition, formalin-fixed, paraffin-embedded samples of 25 seminomas, of which 12 contained carcinoma in situ and 13 spermatocytic seminomas from our tissue archive, were used. Twelve testis samples represent- ing various developmental stages (17, 19, 21, 23, 24, $28,35,37,38$, and 40 weeks) were obtained after autopsy had been performed for reasons unrelated to testis development. These samples were also fixed in formalin and paraffin-embedded. In addition, snapfrozen samples of two gonads, one after 36 weeks of intrauterine development and another that was 7 months post partum, were included.

\section{Immunohistochemistry}

Frozen tissue sections of 5- $\mu \mathrm{m}$ thickness were pretreated with acetone and PBS/BSA 1\%. Antiserum A2 (Meuwissen et al, 1992) against SCP1 (a gift from Dr. C. Heyting, Agricultural University, Wageningen, The Netherlands) was used in a dilution of 1:300 for 60 minutes at room temperature. Detection was done with the avidin-biotin-HRP complex (DAKO AVS, Glostrup, Denmark) using the Vector NovaRED substrate kit (Vector Laboratories, Burlingame, California). Sections were lightly counterstained with hematoxylin.

The paraffin-embedded tissue sections of $3-\mu \mathrm{m}$ thickness were mounted on 3-aminopropyltriethoxysilane (APES)-coated slides and dried at $50^{\circ} \mathrm{C}$ overnight. They were pretreated with a modified heat-induced, antigen-retrieval method (Shi et al, 1991), using $10 \mathrm{~mm}$ citrate buffer, $\mathrm{pH}$ 6.0. Incubation with the primary antibody was done for 60 minutes at room temperature. Detection was performed using the avidin-biotin-alkaline phosphatase complex (DAKO A/S) with New fuchsin (Sigma, St. Louis, Missouri) as chromogen. Sections were lightly counterstained with hematoxylin. Positive (testicular parenchyma containing normal spermatogenesis) and negative (excluding the first antibody) controls were included in each experiment. The antibody XPA Ab-1 Clone 12F5 (Clone 12F5; NeoMarkers, Union City, California) was used in a dilution 1:50, and the antibody SSX (a gift from Dr. A. Geurts van Kessel, Department of Human Genetics, University Hospital, Nijmegen, The Netherlands) was used undiluted. Double staining using the antibodies against c-KIT and SSX was performed as follows. The pretreatment was done as described, after which the primary antibodies were incubated sequentially. The binding of the c-KIT antibody was visualized using avidin-biotin-alkaline phosphatase complex with Fast blue BB (Sigma) as chromogen. Detection of the SSX-specific antibody was done using the peroxidase-anti-peroxidase method with 3-amino-9-ethyl-carbazole (AEC) (Sigma) as chromogen. The XP12RO cells used are XP12RO clones 2 and 3 , which contain only the expression vector pcDNA3.1, and clones 1 and 4, which contain the same expression vector, including the XPA-cDNA. The cells were provided by Dr. J. Masters (Institute for Urology, University College, London, United Kingdom) and Dr. R. Wood (Imperial Research Cancer Fund, Clare Hall Laboratories, South Mimms, United Kingdom). In addition, HeLa cells were used. They were cultured in vitro under standard conditions, and after trypsinization and fixation in formalin, they were 
paraffin-embedded and handled as described for the tissue sections (see above).

\section{Western Blotting}

Protein extracts were prepared by lysing $5 \times 10^{6}$ cells on ice in $40 \mu \mathrm{l}$ of buffer containing $50 \mathrm{~mm}$ Tris- $\mathrm{HCl}$, $\mathrm{pH}$ 7.5; 250 mM NaCl; 1 mm EDTA; 0.1\% Triton- $\times 100$ or $1 \%$ Triton for XPC; $2 \mu \mathrm{g} / \mathrm{ml}$ aprotinin; $2 \mu \mathrm{g} / \mathrm{ml}$ leupeptin; $1 \mu \mathrm{g} / \mathrm{ml}$ pepstatin; and $97 \mu \mathrm{g} / \mathrm{ml}$ phenylmethylsulfonyl fluoride (PMSF). After a 30-minute incubation, the cells were centrifuged at $180 \times g$ for 20 minutes at $40^{\circ} \mathrm{C}$. The supernatant was recovered and protein content determined by the Bradford method. For immunoblotting, 40- $\mu \mathrm{g}$ protein extracts were separated on SDS $10 \%$ polyacrylamide gels. Proteins were transferred to Immobilon P (Millipore Corporation, Bedford, Massachusetts) membranes. For detection of XPA protein, the primary rabbit polyclonal antibody CJ1, raised against recombinant human XPA protein (CJ Jones, unpublished data) was used in a 1/10,000 dilution. This is the same antibody used for the immunohistochemical studies. The membranes were incubated with the primary antibody for 1 hour, followed by incubation for 1 hour with a 1/25,000 dilution of peroxidase-labeled anti-rabbit IgG (Sigma, St. Louis, Missouri). Bands were revealed with an ECL chemiluminescence kit (Amersham, Arlington Heights, Illinois).

\section{Polymerase Chain Reaction}

Total cellular RNA was isolated from 10-15 tissue sections, 20- $\mu \mathrm{m}$ thick, of the snap-frozen tissue samples, ie, four seminomas and four spermatocytic seminomas, using Trizol (Life Technologies, Breda, the Netherlands) as described earlier (Roelofs et al, 1999). The first and last tissue sections (5- $\mu \mathrm{m}$ thick) were stained with hematoxylin and eosin to confirm a percentage of tumor cells of more than $80 \%$ in the samples. All samples were pretreated with RNase free DNase for 30 minutes at $37^{\circ} \mathrm{C}$, and CDNA synthesis was performed as described before (Roelofs et al, 1999). Amplification was done on the equivalent of 125 ng of total RNA. The following primer sets were used: SCP1 5'-GTACAGCAGAAGCAAGCAACTGAATG-3' and 5'GAAGGAACTGCTITAGAATCCAATITCC-3' $\left(\mathrm{T}_{\text {anneal }}=\right.$ $58^{\circ} \mathrm{C}$, resulting in a product of $564 \mathrm{bp}$ ); for XPA 5'-CCTTGTATAAGTAATACTTCAG-3' and 5'-CGTGGAGACAGAAATCGTC-3' $\left(\mathrm{T}_{\text {anneal }}=58^{\circ} \mathrm{C}\right.$, resulting in a product of 340 bp); for SSX3 5'-ATGCCCAAGAAGCCA-GCAG-3' and 5'-AGCCATGCCCATGTTCGTG-3' $\left(\mathrm{T}_{\text {anneal }}=60^{\circ} \mathrm{C}\right.$, resulting in a product of $307 \mathrm{bp})$.

Amplification was done in a volume of $50 \mu \mathrm{l}(50 \mathrm{~mm}$ $\mathrm{KCl} ; 10 \mathrm{~mm}$ Tris, $\mathrm{pH}$ 9.0; 0.1\% Triton X-100; $1.5 \mathrm{~mm}$ $\mathrm{MgCl}_{2} ; 0.25 \mathrm{~mm}$ dATP, dTTP, dCTG, dGTP; 1U Taq Polymerase (Promega, Madison, Wisconsin); and $1 \mu \mathrm{M}$ of each primer. For the seminomas, an aliquot of $25 \mu \mathrm{l}$ was taken after 28 amplification cycles, after which an additional four cycles were run. In contrast, this was done because of saturation for the spermatocytic seminomas after 24 amplification cycles in case of SSX3. An identical approach was done for the housekeeping gene HPRT (primers 5'-CGTGGGGTCCTT-
TTCACCAGCAAG-3' and 5'-AATTATGGACAGGACTG-AACGTC-3' resulting in a product of $387 \mathrm{bp}$ ). This experiment was done on the same microtiter plate and under identical conditions. For each sample, $2.5 \mu \mathrm{l}$ of each amplification product was mixed and loaded on a $1.5 \%$ agarose gel for separation.

\section{Acknowledgements}

We thank the pathologists and urologists in the southwestern part of the Netherlands for their help in collecting the tumor samples. We acknowledge Dr. C. Heyting (Agriculture University, Wageningen, The Netherlands) for the gift of the antibodies against SCP1. Dr. J. Masters (Institute for Urology, University College, London, United Kingdom) and Dr. R. Wood (Imperial Cancer Research Fund, Clare Hall Laboratories, South Mimms, United Kingdom) are acknowledged for help with providing materials of the XP12RO cells.

\section{References}

Adami HO, Bergström R, Möhner M, Zatonski W, Storm H, Ekbom A, Tretli S, Teppo L, Ziegler H, Rahu M, Gurevicius R, and Stengrevics A (1994). Testicular cancer in nine nothern European countries. Int J Cancer 59:33-38.

Burke AP and Mostofi FK (1993). Spermatocytic seminoma. A clinicopathologic study of 79 cases. J Urol Pathol 1:21-32.

Cummings OW, Ulbright TM, Eble JN, and Roth LM (1994). Spermatocytic seminoma: An immunohistochemical study. Hum Pathol 25:54-59.

de Vries A and van Steeg H (1996). Xpa knockout mice. Semin Cancer Biol 7:229-240.

Dekker I, Rozeboom T, Delemarre J, Darn A, and Oosterhuis JW (1992). Placental-like alkaline phosphatase and DNA flow cytometry in spermatocytic seminoma. Cancer 69:993-996.

Delgado R, Rathi A, Albores-Saavedra J, and Gazdar AF (1999). Expression of the RNA component of human telomerase in adult testicular germ cell neoplasia. Cancer 86:18021811.

Dos Santos NR, Torensma R, de Vries TJ, Schreurs MW, de Bruijn DR, Kater-Baats E, Ruiter DJ, Adema GJ, van Muijen GN, and van Kessel AG (2000). Heterogeneous expression of the SSX cancer/testis antigens in human melanoma lesions and cell lines. Cancer Res 60:1654-1662.

Eble JN (1994). Spermatocytic seminoma. Hum Pathol 25: 1035-1042.

Gondos B (1993). Ultrastructure of developing and malignant germ cells. Eur Urol 23:68-75.

Heidenreich A, Sesterhenn IA, Mostofi FK, and Moul JW (1998). Immunohistochemical expression of monoclonal antibody $43-9 \mathrm{~F}$ in testicular germ cell tumours. Int $\mathrm{J}$ Androl 21:283-288.

Herbst H, Kuhler-Obbarius C, Lauke H, Sauter M, MuellerLantzsch N, Harms D, and Loning T (1999). Human endogenous retrovirus (HERV)- $\mathrm{K}$ transcripts in gonadoblastomas and gonadoblastoma-derived germ cell tumours. Virchows Arch 434:11-15. 
Heyting C, Dietrich AJ, Moens PB, Dettmers RJ, Offenberg $\mathrm{HH}$, Redeker EJ, and Vink AC (1989). Synaptonemal complex proteins. Genome 31:81-87.

Hittmair A, Rogatsch H, Hobisch A, Mikuz G, and Feichtinger H (1996). CD30 expression in seminoma. Hum Pathol 27: $1166-1171$.

Jørgensen N, Rajpert-De Meyts E, Graem N, Müller J, Giwercman A, and Skakkebæk NE (1995). Expression of immunohistochemical markers fortesticular carcinoma in situ by normal fetal germ cells. Lab Invest 72:223-231.

Kraggerud SM, Berner A, Bryne M, Pettersen EO, and Fossa SD (1999). Spermatocytic seminoma as compared to classical seminoma: An immunohistochemical and DNA flow cytometric study. APMIS 107:297-302.

Kysela B and Matoska J (1991). Flow cytometry analysis of ploidy and proliferation activity in classical and spermatocytic seminoma. Neoplasma 38:3-11.

Looijenga LHJ, Olie RA, Van der Gaag I, van Sluijs FJ, Matoska J, Ploem-Zaaijer J, Knepfle C, and Oosterhuis JW (1994). Seminomas of the canine testis: Counterpart of spermatocytic seminoma of men? Lab Invest 71:490-496.

Meuwissen RL, Offenberg HH, Dietrich AJ, Riesewijk A, van lersel M, and Heyting C (1992). A coiled-coil related protein specific for synapsed regions of meiotic prophase chromosomes. EMBO J 11:5091-5100.

Møller H (1989). Decreased testicular cancer risk in men born in wartime. J Natl Cancer Inst 81:1668-1669.

Mosselman S, Looijenga LHJ, Gillis AJM, Van Rooijen MA, Kraft HJ, Van Zoelen EJJ, and Oosterhuis JW (1996). Aberrant platelet-derived growth factor alpha-receptor transcript as a diagnostic marker for early human germ cell tumors of the adult testis. Proc Natl Acad Sci USA 93:2884-2888.

Mostofi FK and Sesterhenn IA (1998). Histological typing of testis tumours. Berlin: Springer.

Oosterhuis JW, Castedo SMMJ, De Jong B, Cornelisse CJ, Dam A, Sleijfer DT, and Schraffordt Koops H (1989). Ploidy of primary germ cell tumors of the testis. Pathogenetic and clinical relevance. Lab Invest 60:14-20.

Pousette A, Leijonhufvud P, Arver S, Kvist U, Pelttari J, and Hoog C (1997). Presence of synaptonemal complex protein 1 transversal filament-like protein in human primary spermatocytes. Hum Reprod 12:2414-2417.

Rajpert-De Meyts E and Skakkebæk NE (1994). Expression of the c-kit protein product in carcinoma-in-situ and invasive testicular germ cell tumours. Int J Androl 17:85-92.

Roelofs H, Manes T, Millan JL, Oosterhuis JW, and Looijenga LHJ (1999). Heterogeneity in alkaline phosphatase isozyme expression in human testicular germ cell tumors. An enzyme-/immunohistochemical and molecular analysis. J Pathol 189:236-244.

Roelofs H, van Gurp RJ, Oosterhuis JW, and Looijenga LH (1998). Detection of human endogenous retrovirus type $\mathrm{K}$-specific transcripts in testicular parenchyma and testicular germ cell tumors of adolescents and adults: Clinical and biological implications. Am J Pathol 153:1277-1282.

Romanenko AM and Persidskii YV (1983). Ultrastructure and histogenesis of spermatocytic seminoma. Voprosi Onkologii 19:61-66.
Rosai J, Khodadoust K, and Silber I (1969). Spermatocytic seminoma. Cancer 24:103-116.

Rosenberg C, Bakker Schut T, Mostert MC, Tanke HJ, Raap AK, Oosterhuis JW, and Looijenga LHJ (1999). Chromosomal gains and losses in testicular germ cell tumors of adolescents and adults investigated by a modified CGH approach. Lab Invest 79:1447-1451.

Rosenberg C, Mostert MC, Schut T, van de Pol M, van Echten J, de Jong B, Raap AK, Tanke H, Oosterhuis JW, and Looijenga LHJ (1998). Chromosomal constitution of human spermatocytic seminomas: Comparative genomic hybridization supported by conventional and interphase cytogenetics. Genes Chromosomes Cancer 23:286-291.

Rudolph P, Kellner U, Schmidt D, Kirchner V, Talerman A, Harms D, and Parwaresch R (1999). Ki-A10, a germ cell nuclear antigen retained in a subset of germ cell-derived tumors. Am J Pathol 154:795-803.

Sage J, Martin L, Meuwissen R, Heyting C, Cuzin F, and Rassoulzadegan M (1999). Temporal and spatial control of the Sycp1 gene transcription in the mouse meiosis: Regulatory elements active in the male are not sufficient for expression in the female gonad. Mech Dev 80:29-39.

Schmekel K, Meuwissen RL, Dietrich AJ, Vink AC, van Marle $\mathrm{J}$, van Veen H, and Heyting C (1996). Organization of SCP1 protein molecules within synaptonemal complexes of the rat. Exp Cell Res 226:20-30.

Shi SR, Key ME, and Kalra KL (1991). Antigen retrieval in formalin-fixed, paraffin-embedded tissues: An enhancement method for immunohistochemical staining based on microwave oven heating of tissue sections. J Histochem Cytochem 39:741-748.

Skakkebæk NE (1972). Possible carcinoma-in-situ of the testis. Lancet 2:516-517.

Takahashi H (1993). Cytometric analysis of testicular seminoma and spermatocytic seminoma. Acta Pathol Jpn 43: 121-129.

Talerman A (1980). Spermatocytic seminoma. Cancer 45: 2169-2176.

Talerman A, Fu YS, and Okagaki T (1984). Spermatocytic seminoma. Ultrastructural and microspectrophotometric observations. Lab Invest 51:343-349.

Tureci O, Sahin U, Zwick C, Koslowski M, Seitz G, and Pfreundschuh M (1998). Identification of a meiosis-specific protein as a member of the class of cancer/testis antigens. Proc Natl Acad Sci USA 95:5211-5216.

Van Echten-Arends J, Oosterhuis JW, Looijenga LHJ, Wiersma J, Te Meerman G, Schraffordt Koops H, Sleijfer DT, and De Jong B (1995). No recurrent structural abnormalities in germ cell tumors of the adult testis apart from $i(12 p)$. Genes Chromosomes Cancer 14:133-144.

Walter P (1980). [Spermatocytic seminoma. Study of 8 cases and review of the literature (author's transl)]. Virchows Arch A Pathol Anat and Histol 386:175-187.

Wood RD (1999). DNA damage recognition during nucleotide excision repair in mammalian cells. Biochimie 81:39-44. 